\title{
Tertozoospermia and Recurrent Pregnancy Loss
}

\author{
Khalid A Awartani ${ }^{1 *}$, Maisoon Almugbel ${ }^{1}$ and Serdar Coskun ${ }^{2}$ \\ ${ }^{1}$ Department of Obstetrics and Gynecology, King Faisal Specialist hospital and research centre and AlFaisal University, Saudi Arabia \\ ${ }^{2}$ Department of Pathology, King Faisal Hospital and Research Centre, Saudi Arabia
}

Submission: March 10, 2018; Published: April 30, 2018

*Corresponding author: Khalid A Awartani, Department of obstetrics and gynecology, King Faisal Specialist hospital and research centre and AlFaisal University, Riyadh, Saudi Arabia, Email: kawartani@kfshrc.edu.sa

\begin{abstract}
Objective: To assess the rate of teratozoospermia in a recurrent pregnancy loss (RPL) population and to examine its effect on their reproductive outcome.
\end{abstract}

Material and methods: retrospective cohort study, in a tertiary care referral centre. RPL patients were compared to fertile controls, then the RPL patients were divided in two groups according to the presence or absences of teratozoospermia, both groups were compared for their reproductive outcome.

Result: There were 204 patient in the RPL, and 76 patients in the fertile control group. 41\% of the RPL population had teratozoospermia, compared to $19.7 \%$ of the fertile control (RR 2.1, 95\%CI (1.3-3.5),p=0.001). There was no significant difference in sperm count, or sperm motility between both groups. To assess the effect of teratozoospermia in RPL population, obstetrical outcomes were compared according to presence of teratozoospermia in the RPL group. There were 86 and 118 patients with and without teratozoospermia, respectively. There was no significant difference in the number of losses, the proportion of patients with primary RPL and proportion of losses before positive fetal heart beat seen. Similarly, both group had similar rate of term pregnancies after treatment.

Conclusion: Although teratozoospermia is more commonly seen in RPL population compared to fertile population, it did not have negative impact on the reproductive performance of these patients.

Keywords: Tertozoospermia; Pregnancy loss; Fertile controls; Reproductive outcome; Maternal endocrinological; Genetic; Cytogenetic; Motility; Morphology; Kruger's criteria; Preimplantation; Mann-Whitney; Non-parametric data; Hi-squared test; Sperm motility; Chromosomal abnormality; Lupus anticoagulant; Congenital thrombophilia; Anatomical assessment; Antiphospholipids antibodies; Jeopardized.

Abbreviations: RPL: Recurrent Pregnancy Loss; PGD: Preimplantation Genetic Diagnosis

\section{Introduction}

In this study recurrent pregnancy loss (RPL) was defined as three or more consecutive losses before $20^{\text {th }}$ week of gestation [1], is one of the most frustrated and difficult areas in reproductive medicine. The complexity of the problem led to label multiple factors as associated with the problem rather than as causative; genetic, maternal endocrinological, hematological, and autoimmune disorders have been seen as causative or associated with RPL [2]. The paternal role of associated factors have been a point of debate among multiple authors [3]. The relevance of the male factor in determining RPL still remains unclear. Except for cytogenetic abnormalities in peripheral blood karyotyping, no direct evidence has been reported of any male factor involvement [4].

Some investigators have attempted to evaluate the relationship between sperm parameters as identified on semen analysis, like counts, motility, morphology and more recently DNA fragmentation and certain reproductive outcomes including recurrent pregnancy loss [3,5-9]. Abnormal sperm morphology has been associated with an increased miscarriage rate in couples attending an in-vitro fertilization program in which the male had severe teratozoospermia compare with normal fertile couples [10]. The previous work has used the WHO criteria for assessment of sperm morphology and not the strict Kruger's criteria which are the most commonly used these days. So our aim is to assess the rate of teratozoospermia in the RPL population and to investigate its effects on the reproductive outcome.

\section{Material and Methods}

RPL patients from the RPL clinic in KFSH\&RC, were included in this retrospective cohort study. The control group was chosen from couples undergoing preimplantation genetic diagnosis(PGD) treatment, who are known to be fertile whom coming to the clinic for primary prevention of medical genetic disorders. The data were collected from our electronic database and the charts were reviewed. Semen analysis was performed routinely for both groups and morphological evaluation was 


\section{Global Journal of Reproductive Medicine}

performed according to kruger's strict criteria. Teratozoospermia are defined as having $\geq 96 \%$ abnormal forms, respectively. The primary outcome is the rate of teratozoospermia among RPL population compared to the control group. Then the RPL population will be divided to two groups, group (A)

Consist of RPL population with teratozoospermia, and group (b) Is for the RPL population without teratozoospermia, both groups were compared for the following history of primary RPL (defined as repeated miscarriages in which a pregnancy has never been reached 20 weeks), future pregnancy outcome, history of infertility, maternal age and chromosomal abnormalities. The study was approved by the institutional ethical committee and the Research Advisory Council, with RAC \# 2081032

\section{Statistical analysis}

Statistical analysis was performed using S-plus 2000. Teratozoospermia rate was calculated for the recurrent pregnancy loss and the control group. For the secondary outcome parameters, the two -tailed t-test was used for parametric data, the Mann-Whitney test for non-parametric data, and the Chi-squared test for binomial data. $\mathrm{P}<0.05$ was considered as statistically significant.

Results

Table 1: Semen analysis parameters

\begin{tabular}{|c|c|c|c|}
\hline & RPL n=(204) & $\begin{array}{c}\text { Control } \\
\mathbf{n = ( 7 4 )}\end{array}$ & $\mathbf{P}$ \\
\hline Sperm count (millions) & $210.9 \pm 12.5$ & $\begin{array}{c}203.9 \\
\pm 21.4\end{array}$ & 0.77 \\
\hline Sperm Motility (\%) & $60.2 \pm 1.3$ & $62.1 \pm 2.2$ & 0.44 \\
\hline Sperm Morphology (\%) & $92.4 \pm 0.46$ & $90.4 \pm 0.76$ & 0.02 \\
\hline Teratozoospermia N (\%) & $118(79.9 \%)$ & $59(77 \%)$ & 0.08 \\
\hline $\begin{array}{c}\text { Severe teratozoospermia } \\
\text { N (\%) }\end{array}$ & $86(42 \%)$ & $15(20 \%)$ & 0.001 \\
\hline
\end{tabular}

Data are presented as mean \pm SE unless indicated otherwise.

There were 204 patients in the RPL, and 76 patients in the control group. $42.1 \%$ of the RPL population had teratozoospermia, compared to $19.7 \%$ of the fertile control (RR 2.14, 95\% Cl (1.33.5), $\mathrm{P}=0.001)$. There was no significant difference in sperm count, sperm motility between two the groups (Table 1). To assess the effect of the teratozoospermia in RPL, obstetrical outcomes were compared according to presence of teratozoospermia in RPL group. There were 86 and 118 patients with and without severe teratozoospermia, respectively. Both group had a similar diagnostic work up in regard to their RPL. As shown in (Table 2) there was no significant difference in the number of losses, the proportion of patients with primary RPL and proportion of losses before positive fetal heart beat seen. Similarly, both groups had a similar rate of term pregnancies after treatment according to their diagnosis.

Table 2: RPL history and pregnancy outcome in patients based on teratozoospermia.

\begin{tabular}{|c|c|c|c|}
\hline & $\begin{array}{c}\text { Teratozoospermia } \\
\mathbf{n = ( 8 6 )}\end{array}$ & $\begin{array}{c}\text { No } \\
\text { teratozoospermia } \\
\mathbf{n = ( 1 1 8 )}\end{array}$ & $\mathbf{P}$ \\
\hline Age & $30.8 \pm 4.7$ & $31.5 \pm 5.5$ & 0.4 \\
\hline $\begin{array}{c}\text { Primary } \\
\text { RPL\% }\end{array}$ & 32.5 & 32.2 & 0.9 \\
\hline $\begin{array}{c}\text { Number of } \\
\text { loss in the } \\
\text { past }\end{array}$ & $5 \pm 2.7$ & $4.9 \pm 2.9$ & 0.83 \\
\hline \multicolumn{3}{|c|}{ Pregnancy outcome } & 0.48 \\
\hline $\begin{array}{c}\text { Miscarriage } \\
\text { n(\%) }\end{array}$ & $10(28 \%)$ & $19(37 \%)$ & 0.43 \\
\hline Ongoing n(\%) & $4(11 \%)$ & $4(8 \%)$ & 0.56 \\
\hline Term n(\%) & $22(61 \%)$ & $28(55 \%)$ & \\
\hline \multicolumn{2}{|c|}{} & & \\
\hline
\end{tabular}

Data presented as mean \pm SD unless indicated otherwise

\section{Discussion}

The role of the male factor in RPL is well established when the male is a carrier of balanced structural chromosomal abnormality [2]. Multiple causative and associations have reported to be seen in couples with RPL, but there is still a significant proportion without any identifiable etiology. How much male factors other than chromosomal abnormality contribute to this problem is unknown. Prior studies did not establish a relationship between parameters of the standard semen parameters and RPL $[3,4,8]$. In this study we found that teratozoospermia by strict Kruger's criteria is seen frequently in the male partner of a couple with RPL. When reviewing the data for the pregnancy history for these couples when they presented to the clinic when did not see any implication of poor reproductive performance assessed per number of losses in the past or the stage of pregnancy advancement for these couples as if the severe teratozoospermia is contributing to less quality embryos we might see a difference in the performance of these couples.

Usually our routine work up for these couples include chromosomal analysis for both partners, antiphospholipids antibodies, lupus anticoagulant, congenital thrombophilia, anatomical assessment, and endocrinological assessment. We would treat accordingly, with strict obstetrical follow up by specialized high risk obstetrician. If the couples with teratozoospermia are producing embryos with less quality we would expect that their response to treatment will be somewhat jeopardized by this, we found that patients with teratozoospermia and those without it had similar live birth $[9,10]$. Our data are different from others as we showed higher proportion of teratozoospermia in the RPL population but in concordant with the prior work by Hill et al. [8] which stat that there were no negative effect on future pregnancy outcome. Sperm morphology is not significantly different in male partners of RPL women with respect to controls. We think that semen analysis is of limited use as a test for male factor contribution in RPL, so we suggest omitting this test from the work up of these couples. 


\section{References}

1. Strirrat GM (1990) Recurrent pregnancy loss 1:definition and epidemiology. Lancet 336: 673-675.

2. Ole C, Anne Marie NA, Ernesto B, Salim D, Pater JD, et al. (2005) Evidence-based investigations and treatments of pregnancy loss. Fertility and Sterility 83(4): 821-839.

3. Puscheck EE, Jeyendran RS (2007) The impact of male factor on recurrent pregnancy loss. Curr Opin Obstet Gynecol 19(3): 222-228.

4. Sbracia S, Cozza G, Grasso JA, Mastrone M, Scarpellini F (1996) Semen parameters and sperm morphology in men in uniexplained recurrent spontaneous abortion, before and during a 3 year follow-up period. Hum Reprod 11(1): 117-120.

5. Carrell DT, Liu L, Petrson CM, Jones KP, Hatasaka HH, et al. (2003) Sperm DNA fragmentation is increase in couples with unexplained recurrent pregnancy loss. Arch Androl 49(1): 49-55.

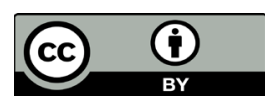

This work is licensed under Creative Commons Attribution 4.0 License DOI: 10.19080/GJORM.2018.04.555640
6. Tesarik J, Greco E, Mendoza C (2004) Late, but not early. Paternal effect on human embryo development is related to sperm DNA fragmentation. Hum Reprod 19(3): 611-615.

7. Gopalkrishnan K, Padwal V, Meherji PK, Gokral JS, Shah R, et al. (2004) Poor quantity of sperm as it affects repeated early pregnancy loss. Arch Androl 45(2):111-117.

8. Hill JA, Abbott AF, Politch JA (1994) Sperm morphology and recurrent abortion. Fertial Sterial 61(4): 776-778.

9. Saxena P, Misro M, Chaki S, Chopra K, Roy S, et al. (2008) Abnormal sperm function an indicator among couples with recurrent pregnancy loss?. Fertil Steril 90(5): 1854-1858.

10. Kruger TF, Acosta AA, Simmons KF, Swanson RJ, Matta JF, et al. (2008) Predictive value of abnormal sperm morphology in vitro fertilization. Fertil Sterial 49(1): 112-117.

\section{Your next submission with Juniper Publishers will reach you the below assets}

- Quality Editorial service

- Swift Peer Review

- Reprints availability

- E-prints Service

- Manuscript Podcast for convenient understanding

- Global attainment for your research

- Manuscript accessibility in different formats

( Pdf, E-pub, Full Text, Audio)

- Unceasing customer service

Track the below URL for one-step submission

https://juniperpublishers.com/online-submission.php 